\title{
Investigation of Cutaneous Leishmaniasis Cases in Baghdad province, Iraq
}

\author{
Aliaa F.A. Al-Naimy ${ }^{1}$, Ali B.M. Al-Waaly ${ }^{1}$

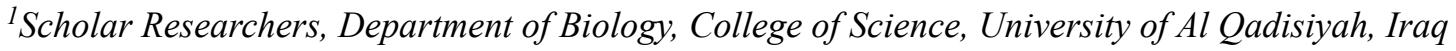

\begin{abstract}
444 cases were recorded of cutaneous leishmaniasis in Baghdad General Hospitals and some private clinics in Baghdad city and reviewed during the period from 1/10/2019 until 5/2020. The lesions were clinically diagnosed by dermatologists. Where the highest incidence was among males compared to females, it was found that the age group of (1-10) and (10-20) is the highest injury and that the rest of the age groups showed a decline. It was clear that the lowest percentage was among (50-60 yrs) patients, and the highest injury among the youth category. The rate of infection was higher in rural and agricultural areas compared to the city center. The infection rates in relation to different body sites are the highest in the upper extremities compared to the lower extremities. And according to the ulcer number, the multiple types were more than the single ulcers, and regarding the time of infection the highest rates of infection appear in December and February compared to the rest of the year.
\end{abstract}

Keywords: Cutaneous Leishmaniasis, Leishmania tropica, major, Leishmania epidemiology.

\section{Introduction}

Cutaneous leishmaniasis is a transmited disease caused by multiple types of leishmania, and it represents a public health problem in society and a danger to people who travel or live in endemic areas ${ }^{(1)}$. About 12 million people are infected in 98 countries with these diseases, with 350 million people are at risk of infection $^{(2)}$. Parasites are transmitted through the bite of the sand fly female, of the genus Phlebotomus in the Old World or the genus Lutzomyia ${ }^{(3)}$. Approximately 1001000 promastigotes are infected into the skin as they are invaded by the neutrophils that spread rapidly at the site of the sting ${ }^{(4)}$. The total number of reported cases of leishmaniasis in the period from 2008 to 2015 in Iraq reached 17001 cases ranging between 2.9-10.5/100,000

\section{Corresponding Author:}

Aliaa F.A. Al-Naimy

Scholar Researchers, Department of Biology, College of Science, University of Al Qadisiyah, Iraq

e-mail: aliafaiq542@gmail.com people ${ }^{(5)}$. Aim of this study to determine investigation of cutaneous Leishmaniasis cases in Baghdad province, Iraq.

\section{Materials and Method}

Study Area: Baghdad is the capital of the Republic of Iraq, and it is in the Tigris Plain Valley in central Iraq, about 39 meters above sea level, between latitudes 33 north and 44 east. Its climate is generally hot. The rainfall rate is $100-175$ each year, 58 between November and March. Average temperatures reach $50^{\circ} \mathrm{C}$ during the summer, and according to ${ }^{(6)}$ the average high temperature is $15.5^{\circ} \mathrm{C}$ (January) to $44^{\circ} \mathrm{C}$ (July), and the average low temperature is $3.8^{\circ} \mathrm{C}$ (January) to $25.5^{\circ} \mathrm{C}$ (July).

Sample Collection: The epidemiological study was conducted on 444 patients suffering from skin lesions of different ages and genders that were diagnosed by dermatologists as leishmaniasis for the people who came to the hospitals of Baghdad, which were included in the study and for the period from $1^{\text {st }}$ October 2019 until May 2020 . 


\section{Diagnosis of Samples:}

Clinical Diagnosis: Clinical diagnosis was made by a dermatologist.

Laboratory Diagnosis: Used direct smear method prepared from the edge of the ulcer and stained using Giemsa then checked for amastigotes by high-power microscope with oil immersion.

Statistical Analysis: The data was analyzed using SPSS statistic software version 25.Chi-square test was used for the assessment of association among the variables studied. The p-value of less than 0.05 was statistically significant, and highly significant for $p$-value of less than $0.001^{(7)}$.

\section{Results}

1. Percentage of people with cutaneous leishmaniasis, by sex: The highest infection rate for males was $55.6 \%$ compared to females at $44.4 \%$, as shown in Table (1). The results of the statistical analysis using Chi-square were used, and there was a significant difference between the infection of cutaneous leishmaniasis and its relationship to gender under the probability level 0.05 .

Table (1): Shows percentages of people with cutaneous leishmaniasis by gender.

\begin{tabular}{|c|c|c|}
\hline Sex & No. of infection & Percentage \\
\hline Male & 247 & 55.6 \\
\hline Female & 197 & 44.4 \\
\hline$X^{2}$ & \multicolumn{2}{|c|}{11.26} \\
\hline$P$ value & \multicolumn{2}{|c|}{ P 0.001(HS) } \\
\hline
\end{tabular}

HS: Highly significant difference $(\mathrm{P}<0.01)$

2. Percentage of patients with cutaneous leishmaniasis, by age:

The proportions of infection with cutaneous leishmaniasis parasite were calculated based on the age groups, where it was found that the age group of (1-10) and (10-20) have the highest infection rate, reaching $(32.0 \%)$ and $(36.0 \%)$, respectively, and that the rest of the age groups showed a clear decline, and the lowest percentage among (50-60 yrs) was (1.0\%), as shown in table (2). The results of the statistical analysis using the Chi-square showed that there were significant differences without infection with cutaneous leishmaniasis and age groups below the probability level 0.05 .
Table (2) Shows the percentages of people with cutaneous leishmaniasis by age

\begin{tabular}{|c|c|c|}
\hline Age group & No. of infected & Percentage \\
\hline $10>$ & 142 & 32.00 \\
\hline $10-20$ & 160 & 36.00 \\
\hline $20-30$ & 67 & 15.00 \\
\hline $30-40$ & 62 & 14.00 \\
\hline $40-50$ & 9 & 2.00 \\
\hline$<50$ & 5 & 1.00 \\
\hline Total & 444 & 100 \\
\hline $\mathrm{X} 2$ & \multicolumn{2}{|c|}{344.41} \\
\hline $\mathrm{P}$ value & \multicolumn{2}{|c|}{$\mathrm{P}<0.0001(\mathrm{HS})$} \\
\hline
\end{tabular}

HS: Highly significant difference $(\mathrm{P}<0.01)$

3. Percentage of patients with cutaneous leishmaniasis, according to the location of the residence: The rates of infection with cutaneous leishmaniasis parasite, according to the location of housing during the current study period showed that the rates of infection increased in Rural areas by $(39.0 \%)$, followed by agricultural areas in the city by $(27.0 \%)$ while the remaining infection rate was in the center of the city urban areas and has shown a decline in injury rates, as shown in Table 3 . The results of the statistical analysis using the Chi-square showed significant differences. The prevalence of cutaneous leishmaniasis in the districts, poor areas, and the city center is below the probability level 0.05 .

Table (3) Shows the percentage of people with cutaneous leishmaniasis, according to the location of the residence.

\begin{tabular}{|l|c|c|}
\hline Region & No. of Infected p. ts & Percentage \\
\hline Assadr & 174 & 39.00 \\
\hline Mahmudiyah & 120 & 27.00 \\
\hline Hosseinieh & 59 & 13.00 \\
\hline Alkaramah & 63 & 14.00 \\
\hline Adhamiya & 28 & 7.00 \\
\hline Total & 444 & 100.0 \\
\hline$X^{2}$ & \multicolumn{2}{|c|}{189.79} \\
\hline P value & \multicolumn{2}{|c|}{$P .0001(\mathrm{HS})$} \\
\hline
\end{tabular}

HS: Highly significant difference $(\mathrm{P}<0.01)$

4. Parasitic infection percentages according to the site of infection from the body: The rates 
of infection in the hands and feet sites are among the areas most affected by parasitic ulcers $(60.0 \%)$ compared to the face (25.0\%). The lowest incidence of ulcer was the back site $(2.0 \%)$, as shown in Table 4. The results of the statistical analysis using the Chi-square showed significant differences. Infection with cutaneous leishmaniasis and its distribution to different areas of the body under the probability level of 0.05 .

Table (4): Shows the percentage of parasitic infection according to the site of infection from the body.

\begin{tabular}{|l|c|c|}
\hline Infection site & Number & Percentage \\
\hline Face & 210 & 25.00 \\
\hline Neck & 81 & 10.00 \\
\hline Chest & 26 & 3.00 \\
\hline Back & 22 & 2.00 \\
\hline Hand & 299 & 36.00 \\
\hline Foot & 198 & 24.00 \\
\hline Total & 836 & 100.0 \\
\hline$X^{2}$ & \multicolumn{2}{|c|}{ P $<0.0001(\mathrm{HS})$} \\
\hline P value & \multicolumn{2}{|c|}{} \\
\hline
\end{tabular}

HS: Highly significant difference $(\mathrm{P}<0.01)$

\section{Discussion}

Distribution of cutaneous leishmaniasis by gender: The results of the statistical analysis of the relationship between cutaneous leishmaniasis and the host's sex showed that males had a higher rate of infection than females with a rate of $55.6 \%$ and $44.4 \%$, respectively. It may be attributed to the fact that males are more exposed to infected vectors than females. Arroub et $a l^{(8)}$ stated that males who work or sleep in the open and rooftop areas with less body coverage are more susceptible than others. Some studies have assumed that the sex difference observed in some parasitic diseases can be attributed to hormonal influences, but the role of sex hormones in the immune response remains controversial $^{(9,10,11)}$. The current study agreed with Mohammad \& Al-Khaliq ${ }^{(12)}$ in Baghdad governorate, where it recorded the highest rates of infection in males with a rate of $(65 \%)$ compared to $(35 \%)$ of females. The study also agreed with Salman et al. ${ }^{(13)}$, where the highest percentage of males was recorded at 56 and $(82.35 \%)$ more than females whose number of injuries exceeded 12 and by (17.64\%). It agrees with Al-Khayyat et al.,
(14) in the governorate of Baghdad, where it recorded the highest rates of infection in males by $(60.3 \%)$ compared to females by $(39.6 \%)$. The study differed with Kattoof, (15) in Baghdad Governorate, where it recorded the highest rate of infection among females, as it reached (24\%) in comparison with males $(21 \%)$. It also differed with what Alawieh et al ${ }^{(16)}$ in his studies in Syria, where he recorded the highest percentage of females (52\%) compared to females $(48.9 \%)$.

Distribution of cutaneous leishmaniasis by age: The current study showed that the highest incidence of cutaneous leishmaniasis is between (10-20) years, with a rate of $(36 \%)$, and the lowest in the age group (5-60) years with a rate of (2\%). Significantly due to the external activities of young people more than other age groups where young people are often ill ${ }^{(17)}$. The low incidence of cutaneous leishmaniasis for older adults may be related to the fact that they were infected during the early ages and acquired long-term immunity during Childhood ${ }^{(9,10,18)}$. The current study agrees with ${ }^{(12)}$, which recorded the highest incidence of cutaneous leishmaniasis in the age groups between 5-24 years more than others $(67.5 \%)$. The current study differs with Al-Mafraji et al., ${ }^{(19)}$ in Baghdad governorate, where the highest rates of infection were recorded for ages under 30 years of age from the youth category (42.6\%). The study differed with Al-Mayali \& Al-Hassani, ${ }^{(3)}$ in Diwaniyah governorate, where the highest incidence of cutaneous leishmaniasis was recorded for less than 5 years of age group $34.7 \%$.

Distribution of cutaneous leishmaniasis according to residence: The obtained results showed that the rates of infection increased in the agricultural areas, districts, and poor neighborhoods, where they increased in Sadr City by $39 \%$, followed by the Mahmudiyah District by $27 \%$ and the lowest in the Adhamiya region by $7 \%$, attributed to the increase in the highest rates of infection in the agricultural and districts And slum areas due to the abundance of poor hosts that store the disease, which leads to an increase in the chances of infection with the parasite throughout the year, and it increases especially in agricultural areas due to the continuous cultivation of it in all seasons of the year, while this percentage decreases in urban areas. ${ }^{(9,20)}$. The study agreed with Kashkool, ${ }^{(21)}$ reported the highest infection rates in rural and agricultural areas, reaching 317 (92.4\%), and the lowest injury was recorded in urban areas, reaching 26 (7.6\%). The current study also agreed with Al-Mashhadany, ${ }^{(22)}$; Al-Mayali \& Al-Hassani, ${ }^{(3)}$; Khudhur, ${ }^{(23)}$ they recorded 
the highest rates of infection in agricultural and rural areas and the lowest infection in urban areas. They also agree with Reda, ${ }^{(12)}$ in Babel governorate, where the highest rates of infection were recorded in agricultural regions with a rate of $(55 \%)$ followed by the districts with $(25 \%)$ and the lowest percentage in the city center with a rate of (20\%). The study differed with Kattoof, ${ }^{(15)}$ in Baghdad governorate, where the highest rate of infection was recorded in urban areas, at a rate of $(28 \%)$, compared to rural areas and poor neighborhoods, at a rate of $(18 \%)$. The study also came different with what Luma $^{(24)}$ found In the city of Babel, where the highest incidence of cutaneous leishmaniasis in urban areas was $32(53.3 \%)$ more than in rural areas $28(46.7 \%)$.

\section{Conclusions}

The Leishmania parasite infects both sexes and all ages without exception and the highest incidence was for young people, and infection were also recorded that the highest incidence was in January and February, while multiple ulcers occupied the largest proportion of ulcers and the most affected sites were the hand and face compared to different body sites. The city of Baghdad is one of the cities where cutaneous leishmaniasis is endemic, as infection varies according to the difference in regions.

\section{Conflict of Interest: None}

\section{Funding: Self}

Ethical Clearance: Not required

\section{References}

1. Youssef NG. Black Fever. Scientific bulletin. Najaf Health Department, Primary Care Department. Ministry of Health, 2002. p. 119.

2. Khazaei S, Hafshejani AM, Saatchi M, Salehiniya $\mathrm{H}$ and Nematollahi S. Epidemiological aspects of cutaneous leishmaniasis in Iran. Archives of Clinical Infectious Diseases, 2015. 10(3), 218-222.

3. Al-Mayali HMH and Al-Hassani MKK. Morphological Descriptive Study of Phlebotominae Species (Diptera: Psychodidae) in Eastern AlHamza District, Al-Diwaniya City. Int. J. Curr. Microbiol. App. Sci, 2016. 5(9), 667-674.

4. Al-Hassani MKK and Al-Mayali HMH. Evaluation of some biochemical levels in patients with Cutaneous leishmaniasis serum and their relationship with antioxidant enzymes. Eurasian
Journal of Biosciences, 2020. 14(1), 1999-2006.

5. Al-Obaidi JM, Abd Al-Hussein MY and Al-Saqur IM. Survey Study on the Prevalence of Cutaneous Leishmaniasis in Iraq. Iraqi Journal of Science, 2016. 57(3), 2181-2187

6. Ncci NGO. Coordination Committee for IRAQ. Sulaymaniyah Governorate Profile. 2015.

7. Sheskin DJ. Handbook of parametric and nonparametric statistical procedures. 3rd ed. Boca Raton: Chapman \& Hall/CRC, 2004, 1-77.

8. Arroub H, Alaoui A and Habbari K. Etude EcoEpidemiologique de la Leishmaniose Cutanée dans la Région de Foum Jamâa (Azilal, Maroc). In Le Premier Colloque International sur les Changements Climatiques et Environnement. Faculté des Sciences, Rabat, Maroco. 2010.

9. Al-Waaly ABM and Shubber HWK. Epidemiological study of Cutaneous leishmaniasis in Al-Diwaniyah province, Iraq. EurAsian Journal of BioSciences, 2020. 14(1), 269-273.

10. Al-Myahy FS, Al-waaly ABM and Shubber HW. Laboratory diagnosed for some diseases in AlDiwaniya province. Journal of Al-Qadisiyah for Pure Science (Quarterly), 2009, 14(1), 44-57.

11. Bailey $M$ and Lockwood D. Cutaneous leishmaniasis. Dermatol. 2007; 25:203-211. College of Science, University of Baghdad: 2007, 116 pages.

12. Mohamed Reda AZ. Epidemiological and immunological study of cutaneous leishmaniasis in Al-Kifel, Babylon governorate Iraq. Msc thesis, University of Kufa, Iraq. 2018.

13. Salman IS, Vural A, Unver A and Sacar S. Cutaneous leishmaniasis cases in Nizip, Turkey after the Syrian civil war. Mikrobiyol Bul, 2014. 48(1), 106-13.

14. Al-Khayat H, Gurganus C, Newcomb DE and Sakhaeifar MS. Developing Specification Limits for Hot Mix Asphalt Properties and Impact on Pay Factors. Journal of Transportation Engineering, Part B: Pavements, 2020. 146(3), 502-507.

15. Kattoof WM. Intralesional streptomycin: New, safe, and effective therapeutic option for cutaneous leishmaniases. Mustansiriya Medical Journal, 2018. 17(1), 42-46

16. Alawieh H, Tehrani KA, Azzouz Y and Dakyo B. A new active common-mode voltage elimination 
method for three-level neutral-point clamped inverters. In IECON 2014-40th Annual Conference of the IEEE Industrial Electronics Society, 2014. 1060-1066.

17. Akcali C, Çulha $\mathrm{G}$, İnalöz HS, Savaş $\mathrm{N}$, Önlen $\mathrm{Y}$, Savaş L and Kırtak N. Cutaneous Leishmaniasis in Hatay. Turkey Published: J Turk Acad Dermatol 2007. 1(1),1-16.

18. Zaph C, Uzonna J, Beverley SM and Scott P. Central memory $\mathrm{T}$ cells mediate long-term immunity to Leishmania major in the absence of persistent parasites. Nature medicine, 2004, 10(10), 1104-1110.

19. AL-Mafraji KH, Al-Rubaey $\mathrm{MG}$ and Alkaisy KK. Clinco-eidemiological Study of cutaneous leishmaniases in AL-Yarmouk Teaching Hospital. Iraq Journal Community, 2008. 21(3), 194-197.

20. Kassiri H, Mortazawi $\mathrm{H}$ and Kazimi SH. The epidemiological study of cutaneous leishmaniasis in Khorramshahr city, Khouzestan Province,South- west of Iran. Jundishapur J. Health Sci, 2011. 3, 11-20.

21. Kashkool AH. Some ecological and biological aspects of phlebotominae (Diptera; Psychodidae) and the epidemiology of cutaneous leishmaniasis in Diwaniya Governorate". M.Sc. thesis, college of sciences, University of Al-Qadisiya, Iraq. 2009.

22. Al-Mashhadany W. Present status of cutaneous Leishmaniasis and its vectors in Baghdad area. M.SC. Thesis, College of science, University of Baghdad, Iraq. 2002.

23. Khudhur HR and Alomashi GB. Effect of NRAMP1 gene polymorphism on levels of (TNF- $\alpha 1$ and IL$1 \beta)$ cytokines in cutaneous Leishmaniasis patients in Iraq. Journal of Immunology and Clinical Microbiology, 2018. 3(2), 15-22.

24. Luma AH. Molecular study for cutaneous leishmaniasis and its relation parameters in patients of Al-Najaf Al-Ashraf province. PhD. Thesis, AlQadisiya University, Iraq. 2019. 